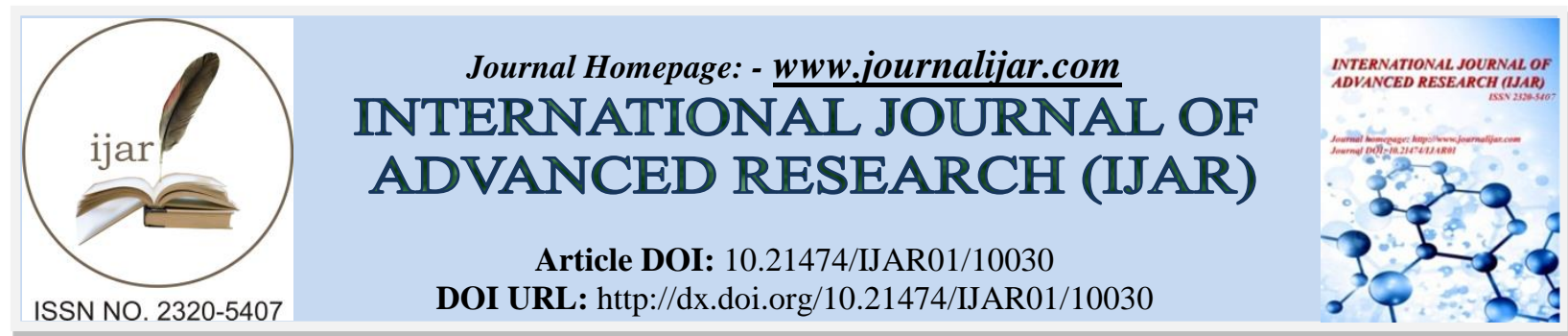

RESEARCH ARTICLE

\title{
GIANT CELL MANDIBL GRANULOMA ABOUT ONE CASE.
}

M.Mennouni, H.Ardhaoui, S.Rouadi, R.Abada, M.Roubal and M.Mahtar.

\section{Manuscript Info}

Manuscript History

Received: 10 September 2019

Final Accepted: 12 October 2019

Published: November 2019

\section{Abstract}

Giant cell granuloma is an infrequent benign lesion of the maxillae, sometimes she presents an aggressive behavior [1]. It is characterized by destruction of the bone, loss of facial symmetry, this lesion occurs more frequently in women than in men with a location twice as common in the mandible than in the maxilla.

Our case is about a 46-year-old patient with no previous history, presenting a painless and fixed mandibular swelling and in whom a panoramic radio showed a lytic lesion, maxillofacial CT had described an aspect in favor of bone metastasis probably of thyroid origin.

Copy Right, IJAR, 2019,. All rights reserved.

\section{Introduction:-}

Giant cell granuloma is an infrequent benign lesion of the maxillae, sometimes she presents an aggressive behavior [1]. It's characterized by destruction of the bone, loss of facial symmetry, this lesion occurs more frequently in women than men with a location twice as common in the mandible than in the maxilla. The etiology of the GRCG remains poorly understood. In the majority of cases, the lesions are asymptomatic, painless, with slow-growing intra-oral swelling. Radiologically, the image described will be ranging from a small unilocular lesion to a large multilocular lesion associated with tooth displacements, root resorptions or even perforations of the bone cortical. However, the diagnosis will be confirmed only by histological examination [2].

It is a peripheral brown tumor which is related to hyperparathyroidism, she represent giant cell peripheral lesions. The clinical, radiological and histological features of these lesions are univocal and the differential diagnosis is only biological, based on the serum parathyroid hormone test. Histological examination differentiates giant cell peripheral lesions from hyperplastic lesions of reactive origin [3]

\section{Observation:-}

A 46-year-old patient with no previous history, presenting a cervical swelling evolving for 2 years mobile and ascending on swallowing, the lower limit is not palpable, the symptomatology was complicated by hard and fixed painless mandibular swelling Cervical ultrasound objectified an enlarged thyroid gland seat of multiple heterogeneous nodules of which the largest measuring $12.7 \quad * \quad 10.5 \mathrm{~mm}$ Panoramic Radio showed a lytic image that depends on the body of the mandibular bone

A phosphocalcic assessment was carried out to eliminate a brown tumor of the maxillae which is related to hyperparathyroidism. The results obtained were normal for all the parameters studied. The biological assessment showed no abnormality: parathyroid hormone PTH 39.35pg / ml Calcium $84 \mathrm{mg} / 1$.

Corresponding Author:-M.Mennouni. 
Maxillofacial CT had shown aspect in favor of bone metastasis probably of thyroid origin Figure 1 MIBI-TC99m Parathyroid Imaging shows a focus of retention in favor of parathyroid origin (adenoma) Figure 2 following these results a mandibular biopsy had been made objectifying a giant cell granuloma

The patient underwent exo-oral surgical management, at the exploration the tumor was fleshy, reddish brown, very hemorrhagic and friable, throughout the excision phase. A large tumorectomy was done with margins of excision respected a total thyroidectomy was performed at 15 days apart, the parathyroid glands were respected Figure 3 Total thyroidectomy was performed 15 days after histopathological examination which was dystrophic.

A good evolution was observed in the patient with a follow-up of 6 months

\section{Discussion:-}

Giant central granuloma (GCCG) is a benign tumor that is part of giant cell tumors and pseudo-tumors still poorly understood. According to the OMS classification tumors and pseudo tumors are part of a polymorphous tumor group of non-odontogenic origin that includes all Maxillary tumors of conjunctive origin [4]

The nosologic framework, however, remains unclear because of an etiopathogenesis which makes it rather a reaction process and not a real neoplasia. The nosological appreciation is more different in the Anglo-Saxon countries and in France. Indeed, the Forest School [5] establishes a nuance between restorative cell granulomas for maxillary lesions that are distinguished from "giant cell reactions" for lesions affecting the small bones of the extremities: metatarsal, metacarpal and phalanges. This distinction is not taken up either by the Anglo-Saxon authors, or by Campanacci [6] who group these entities under the same name of reparative giant cell granuloma [7]

The GCCG meets primarily in the mandible in the young woman. Few cases have been described with maxillary localization, in a woman nearly 30 years old. The peculiarity of this lesion lies in the difficulty of its clinical and radiographic diagnosis. Its nonalgic evolution, can simulate a chronic odontogenic cellulitis, especially since it is located on a ground devoid of general signs. In some cases like this, the diagnostic orientation is complicated. [4] with a real difficulty that lies in the differential diagnosis with giant cell tumor (GCT).

Giant cell lesions of the maxilla include the brown tumor of hyperparathyroidism, the true giant cell tumor and the giant cell repair granuloma [8, 9]. The brown tumor is, in the majority of cases, linked to primary hyperparathyroidism, It results in more than $80 \%$ of cases of a parathyroid adenoma, more rarely of hyperplasia and exceptionally of parathyroid carcinoma [10], a biopsy will confirm the positive diagnosis and eliminate the suspicion of any other giant cell lesion.

The TCG is reddish-brown sometimes necrotic or pseudo-cystic with many giant cells in a matrix low in collagen and rich in fusiform cells. Its recurrence rate is significantly higher, nearly $50 \%$, with a risk of malignant transformation in sarcoma of nearly 10 to $20 \%$ [11].

Currently the conventional treatment of the GRCG is surgical and consists of curettage associated or not with an excision. A 2005 study by De Lange et al., Conducted in Germany on 80 patients presenting with a GRCG (16 aggressive cases and 64 non-aggressive cases) and all treated by curettage, reported a recurrence in $26.3 \%$ of cases, within a period of 0 to 10 years (De Lange and Van Den Akker, 2006) [12]. The 2006 Kruse-Losler study of 26 patients (10 aggressive cases and 16 non-aggressive cases) treated with curettage and surgical resection, reported a recurrence of $11.5 \%$ within 9 months to 12 years [13].

Other less invasive therapies have had favorable results with intra-lesional administration of corticosteroids [14]. However, currently, no controlled clinical study is published regarding this therapy. Other authors have also demonstrated the favorable role of calcitonin in the treatment of GRCG [15, 16, 17] Interferon® administered as monotherapy in the treatment of aggressive GRCG, also seems able to interrupt the growth of lesions, sometimes to reduce the size. It is often necessary to add surgery to eliminate the lesion [18, 19] Radiotherapy remains reserved for recurrent or unresectable cases [1]

While many case reports have shown good results in non-surgical therapies, the data are not statistically significant. The majority of studies present the surgical procedure as the "gold standard" in the treatment of this type of tumor, and as such, have oriented our therapeutic choices in the presented clinical case. However, surgical excision remains 
mutilating physically, with significant psychological repercussions for the patient (usually very young). Randomized clinical trials of the combination of calcitonin, interferon $\alpha$ or corticosteroids with minimally invasive surgical curettage should be performed [4]

Finally, it is important to emphasize the importance of early detection and knowledge of the diagnostic elements of this type of tumor, which is often benign, but whose destructive consequences are disabling.

\section{Conclusion:-}

Giant central granuloma (GCCG) is an uncommon tumor in maxillary surgery. Its scarcity and numerous differential diagnoses lead to diagnostic difficulties that call for a rigorous approach requiring not only careful interrogation but also a careful clinical examination, complete imaging, a targeted biological assessment and an anatomopathological analysis. A giant cell lesion of the maxillae should systematically search for primary hyperparathyroidism by the practice of a calcium phosphate test and a parathyroid hormone test. The diagnosis of primary hyperparathyroidism allow to avoid operating the brown tumors of the maxillae, which should regress after excision of the parathyroid lesion.

The currently available bibliographic data concerning the different possible treatments of giant cell granuloma (GCCG) show that surgery is the conventional treatment with the least recurrence.
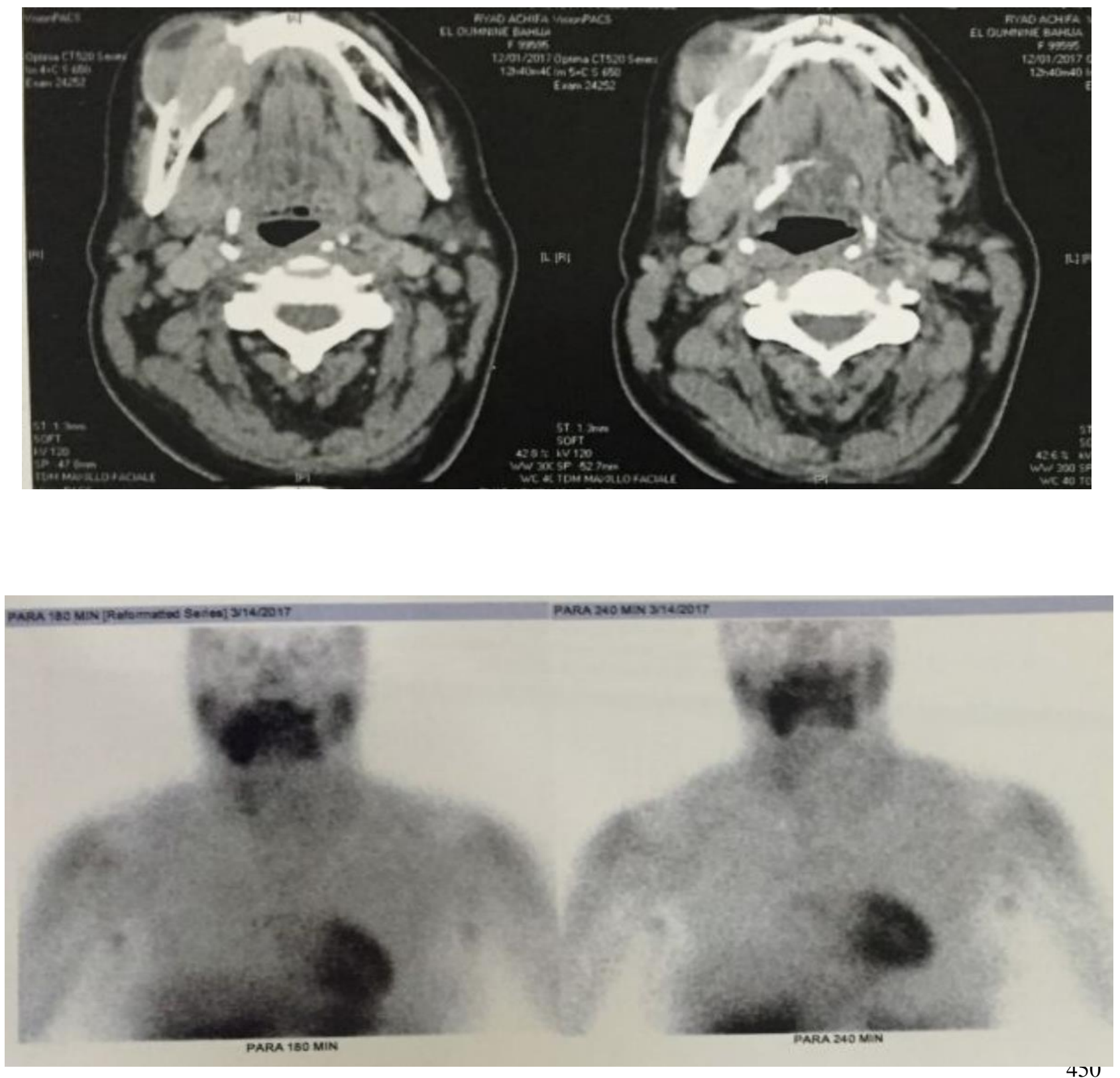


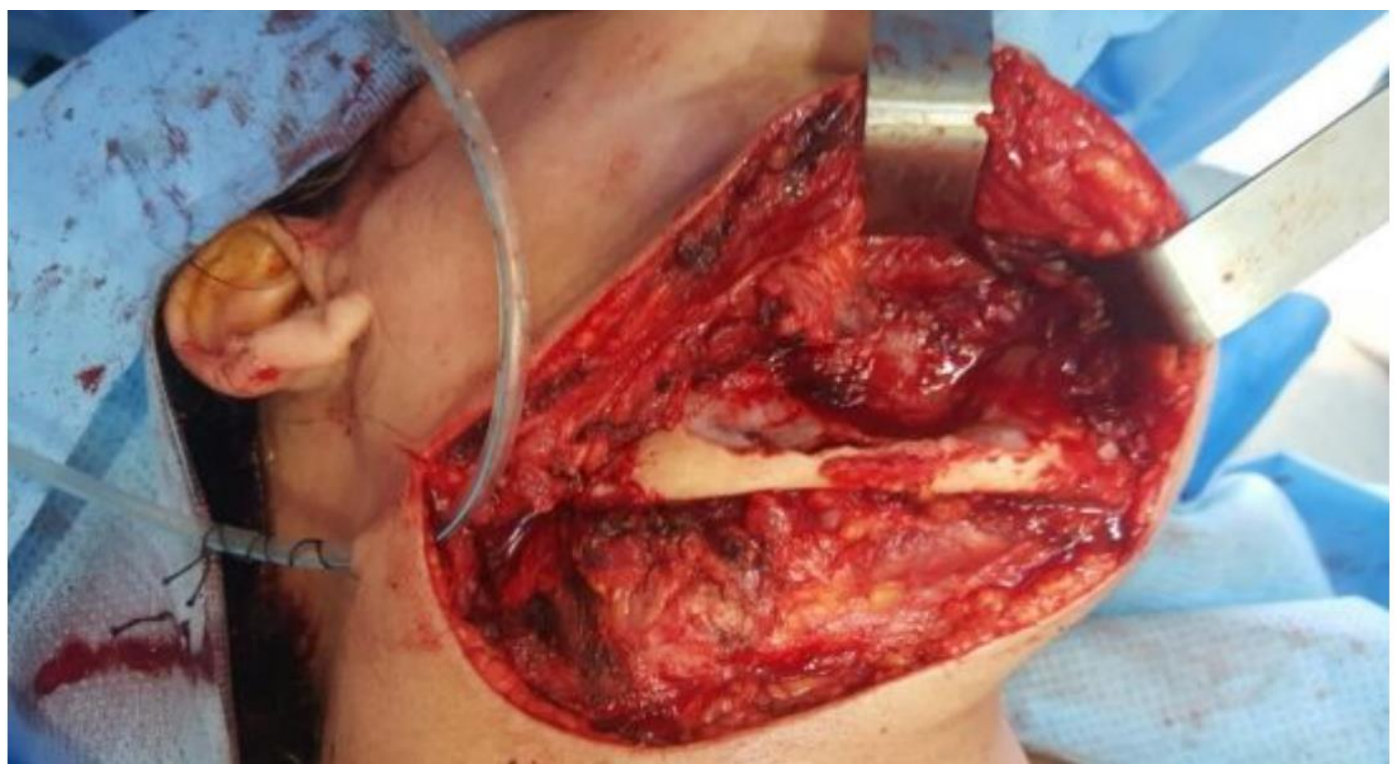

\section{Bibliographie:-}
1. J.
HAMAMA,
L. KHALFI,
H. SABANI,
M.K.
EL KHATIB

Service de Stomatologie et Chirurgie plastique Hôpital militaire d'instruction Mohammed V - Rabat - Maroc

2. STAVROPOULOS

F.,

KATZ

$\mathrm{J}$.

Central giant cell granulomas: a systematic review of the radiographic characteristics with the addition of 20 new cases. Dentmaxilfac Rad 2003;31:213-217.

3. Saliha Chbicheb, Abdelkader Bennani, Karima El Harti, Wafaa El Wady Lésions périphériques à cellules géantes des maxillaires Service d'Odontologie chirurgicale, CCTD, CH Ibn Sina, Rabat, Maroc

4. Victorin AHOSSI, Séverine VINCENT, Christian DUVILLARD, Patrick LARRAS, Tony PETRELLA, Daniel PERRIN. Service Odontologie, CHU Dijon.

5. Abelanet RTumeurcellules géantes des os : anatomie pathologique. In: Tomeno B, Forest M, editors. Les tumeurs osseuses de l'appareil locomoteur. Paris: Schering-Plough; 1990. p. 267-80.

6. Campanacci

Bone and soft tissue tumors. New York: SpringerVerlag; 1999 (p. 901-5).

7. D. Rozé, P. Libersa, J.-C. Libersa, D. Deroubaix, Granulome réparateur central à cellules géantes (GRCCG) Service d'odontologie, CHRU Lille

8. Yamazaki $\mathrm{H}, \quad$ Ota $\mathrm{Y}, \quad$ Aoki $\mathrm{T}, \quad$ Karakida $\mathrm{K}$. Brown tumor of the maxilla and mandible: Progressive mandibular brown tumor after removal of parathyroid adenoma. J Oral Maxillofac Surg 2003; 61:719-722.

$\begin{array}{llll}\text { 9. Marthan } & \text { E, Antin } & \text { B } & \text { Goujon } \\ \text { Granulome réparateur à cellules géantes. Rev Stomatol Chir Maxillofac 1996;97:161-165. }\end{array}$

M.

10. Shanmuchan MS, Alhady SF. Hyperparathyroidism with osteitis fibrosa cystica in the maxilla. J Laryngol 1984;98: 417-422.

11. BARTHÉLÉMY

$\mathrm{I}$,

MONDIÉ

$\mathrm{J}-\mathrm{M}$.

Giant cell tumors and pseudogiant cell tumors of the jaws.Rev Stomat chir maxilfac 2009; 110:209-213

12. $\mathrm{DE}$ LANG J., VAN

DEN

AKKER

H.P.,

KLIP

H. Incidence and disease-free survival after surgical therapy of central giant-cell granulomas of the jaw in The Netherlands:1990-1995. Head Neck 2004;26:792-795

13. KRUSE-LOSTER B., DIALlO R., GAERTNER C., MISCHKE K.L., JOOS U., KLEINHEINZ J. Central giant cell granuloma of the jaws : a clinical, radiologic, and histopathologic study of 26 cases. Oral Surg Oral Med Oral Path Oral Rad Endo 2006;101:346-354.

14. EL

HADIDI

$\mathrm{YN}$,

GHANEM

AA,

HELMY

I.

Injection of steroids intralesional in central giant cell granuloma cases (giant cell tumor): Is it free of systemic complications or not? A case report.Int J Surg Case Rep. 2015; 8C:166-70. 
15. DE LANGE J, VAN DEN AKKER H.P., VELDHUIJZENVAN ZANTEN G.O., ENGELSHOVE H.A.,VAN DEN BERG

H.,

KLIP

H.Calcitinin therapy in central giant cell granuloma of the jaw:a randomized double-blind placebo-controlled study. Int J Oral Maxilfac Surg 2006 a; 35:791-795.

16. O'REGAN E.M, GIBB

D.H.,

ODELL

E. W.Rapid growth of giant cell granuloma in pregnancy treated with calcitonin. Oral Surg Oral Med Oral Path Oral Rad Endod 2001; 92:532-538.

17. POGREL

M.A. Calcitonin therapy for central giant cell granuloma. J Oral Maxilfac Surg 2003; 61:649-653.

18. DE LANGE J, VAN DEN AKKER H.P, VAN DEN BERG H., RICHEL D.J, GORTZAK RAT. Limited regression of central giant cell granuloma by interferon alpha after failed calcitonin therapy: a report of two cases. Int J Oral Maxillofac Surg 2006 b; 35:865-869.

19. Victorin .A, VINCENT. S, DUVILLARD. C, LARRAS. P, PETRELLA. T, PERRIN .D. Granulome réparateur à cellules géantes du maxillaire : à propos d'un cas .Rev Odont Stomat 2010;39:135-144 